\title{
Electrical Injury and Prolonged Cardiac Arrest: A Case Report of Complete Neurological Recovery
}

\author{
Uma Hariharan, MBBS, DNB, PGDHM, CCEPC, FICA, MNAMS, DESA ${ }^{\prime *}$;Vinoth Natarajan,MBBS, MD² \\ 'Anaesthesiology, Dr. Ram Manohar Lohia Hospital and Atal Bihari Vajpayee Institute of Medical Sciences-PGIMER, New Delhi, India \\ ${ }^{2}$ Anaesthesiology and Intensive Care, MGM Health Care, Chennai, Tamil Nadu, India

\section{${ }^{*}$ Corresponding author} \\ Uma Hariharan, MBBS, DNB, PGDHM, CCEPC, FICA, MNAMS, DESA \\ Associate Professor,Anaesthesiology, Dr Ram Manohar Lohia Hospital and Atal Bihari Vajpayee Institute of Medical Sciences-PGIMER, New Delhi, India; \\ E-mail: umal708@gmail.com
}

\section{Article information}

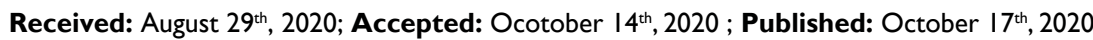

\section{Cite this article}

Hariharan U, Natarajan V. Electrical injury and prolonged cardiac arrest:A case report of complete neurological recovery. Emerg Med Open J. 2020; 6(I): 3-5. doi: $10.17 \mid 40 / E M O J-6-155$

\section{| ABSTRACT |}

\section{Introduction}

Sudden cardiac arrest continues to have a high mortality rate. Out of hospital cardiac arrest (OHCA) has a poor outcome compared to those occurring in a healthcare setup due to lack of awareness and appropriate resources. The most common rhythm abnormality in OHCA is ventricular fibrillation which requires early defibrillation, ideally on the location.

\section{Case Report}

A 19-years male was witnessed by lay bystanders to have become unresponsive following contact with an electric lighting pole on the road median in Chandigarh. A passer-by medical resident detected no pulse and initiated chest compression. Since there was no immediate return of spontaneous circulation and aetiology suggested a defibrillate rhythm. The patient was taken in the car and rushed to a tertiary care centre, 10 -minutes away. Cardiopulmonary resuscitation (CPR) was interrupted during transport for lack of adequate personnel. Ventricular fibrillation was noted and shock was delivered along with inotropes. Around 26-minutes into the resuscitation, the patient had the return of spontaneous circulation. After post-cardiac arrest care in intensive care unit (ICU), he was extubated and discharged home in 1-week with full neurological recovery.

\section{Discussion}

Recovery of full neurologic function could be explained by the alternating presence of stable and unstable cardiac rhythms and in part at least brought about by immediate attempts at resuscitation. The report seeks to review these aspects of emergency care besides highlighting the need for both immediate and accurate emergency medical services such as lay responder training, public access defibrillation and responsive transport systems for such patients.
\end{abstract}

\section{Keywords}

Sudden cardiac arrest; Out of hospital cardiac arrest; Ventricular fibrillation; Early defibrillation; Electrical injury.

\section{INTRODUCTION |}

$S^{3}$ urvival from the out of the hospital cardiac arrest is less than $15 \%$ and it is even very low in developing nations. Out of hospital cardiac arrest (OHCA) has poor outcome compared to those occurring in a healthcare setup due to lack of awareness and appropriate resources. The most common rhythm abnormality in out of hospital cardiac arrest is ventricular fibrillation which requires early defibrillation, ideally on the location. ${ }^{1}$ We described here a case of a young adult male who sustained electrical shock injury while crossing the road, followed by cardiac arrest which was revived by prolonged effective cardiopulmonary resuscitation (CPR) resulting in a complete neurological recovery.

\section{CASE DESCRIPTION}

A 19-years male was witnessed by lay bystanders to have become unresponsive following contact with an electric lighting pole on the road median. A passer-by medical resident detected no pulse and initiated chest compressions. The patient was immediately 
rushed to the nearest hospital and CPR was continued during the transport. Patient was received in Emergency Department and current American College of Cardiology/American Heart Association (ACC/AHA) Advanced Cardiac Life Support (ACLS) PROTOCOLS were followed. Ventricular fibrillation was noted on rhythm assessment and direct-current (DC) shock of $200 \mathrm{~J}$ was delivered, followed by continuation of CPR. By this time, Airway was secured with endotracheal tube of appropriate size. After 4 boluses of adrenaline, Amiodorane $150 \mathrm{mg}$ infusion and also 4 times of DC shock, the patient had the return of spontaneous circulation around 26-minutes into the resuscitation. Then, noradrenaline and adrenaline infusions were started and the patient was shifted to the intensive care unit (ICU). Patient was connected to mechanical ventilation in ICU, central line and arterial line were secured. Mild acidosis was present in arterial blood gas and correction was given. All basic investigations and echocardiography were taken and founds to be normal for this patient. Then patient was gradually weaned off from the ventilator, extubated and shifted to ward. And also he was discharged home within 1-week with full neurological recovery. On follow-up after 15-days in Out-PatientDepartment (OPD), he was perfectly normal with mild generalised bodyache only for which he was prescribed some analgesics too.

\section{DISCUSSION}

Electrical shock injuries cause a wide range of injuries from nil damage to serious life-threatening conditions like sudden death, depending upon the voltage and the duration of the current passing through the body. The response of cardiac muscle to electroshock results in loss of its function and leads to fibrillation. Ventricular fibrillation is the most common rhythm disturbance following the electric shock injury. ${ }^{2}$ Most of the cardiac arrests are reverted back to the normal rhythm if the resuscitation efforts started within 10-minutes. After that, there will be the decrease in the perfusion of vital organs resulting in the serious consequences. But in our case, even though proper resuscitative efforts were started nearly after 12-minutes, the patient had the complete neurological recovery at the time of discharge. Emergency Medical Service personnel and ambulances were not available immediately and hence the patient was taken to nearest hospital by bystander medical resident. Cervical stabilization and chest compressions had not been maintained properly during transportation due to lack of adequate personnel. Wik et $\mathrm{al}^{3}$ in 2003 suggested to give a prime importance to early defibrillation than chest compressions but however recent study done by Hyuang et $\mathrm{al}^{4}$ in 2014 gave equal importance to both chest compression and defibrillation for the out of hospital cardiac arrest cases. And also, recent ACLS update 2015 also emphasizes that whenever automatic external defibrillator (AED) is immediately available, defibrillation should be given as soon as possible for witnessed cardiac arrest. If it is not available, then it is reasonable to initiate chest compressions until the defibrillator equipment is being retrieved and applied. But in this case, defibrillation was given once after we had reached the hospital which was approximately 16-minutes from cardiac arrest scenario. Add-ons such as hypothermia had not been given to this patient which is contrary to the mild therapeutic hypothermia requirement at the post-return of spontaneous circulation
(ROSC) status suggested by Puri et al..$^{5} \mathrm{~A}$ recent high quality study compared temperature management at $36{ }^{\circ} \mathrm{C}$ and at $33{ }^{\circ} \mathrm{C}$ and found outcome to be similar for both. ${ }^{6}$ Recovery of full neurologic function in this case could be explained by the alternating presence of stable and unstable cardiac rhythms of the victim and in part at least brought about by immediate attempts at resuscitation. Other reasons could be young age, witnessed arrest, proximity to hospital, lack of traffic with good road and also the people familiar with the hospital. This report envisages the importance of early chest compressions initiated by medical student on witnessing a cardiac arrest victim and also depicts the usefulness of providing early sophisticated treatment like defibrillation. Automated external defibrillators are the one which provides the effective treatment to the out of the hospital cardiac arrest victim and installation of it in common public gathering places would prevent the unwanted deaths of such victims. Many developed nations have included the installation of automated external defibrillators in common places in their laws itself. Further efforts in this direction are needed in developing nations like India.

\section{CONCLUSION}

Patient's sustained cardiac arrests following electrical injury are readily covered without any neurological deficits if sophisticated treatment is administered at the earliest possible time with good post-resuscitative care. Installing the automated external defibrillators in common places should be carried out effectively and also the training programmes for the special group of people how to use it properly should also be started to reduce the incidence of unwanted deaths from out of the hospital reach cardiac arrests.

\section{SOURCE OF FUNDING}

\section{Nil}

\section{CONSENT}

Written informed consent was taken from the patient for reporting this critical event and successful management.

\section{CONFLICTS OF INTEREST}

The authors declare that they have no conflicts of interest.

\section{REFERENCES}

1. Frõhlich GM, Lyon RM, Sasson C, Crake T, Whitbread M, Indermuehle A, et al. Out-of-hospital cardiac arrest-optimal management. Curr Cardiol Rev. 2013; 9: 316-324. doi: 10.2174/1573403x1 0666140214121152

2. Ahmad M, Shabbir K. Electrical shock survival after prolonged cardiopulmonary resuscitation. J Coll Physicians Surg Pak. 2013; 23: 502-503.

3. Wik L, Hansen TB, Fylling F, Steen T, Vaagenes P, Auestad BH, 
et al. Delaying defibrillation to give basic cardiopulmonary resuscitation to patients with out-of-hospital ventricular fibrillation: A randomized trial. JAMA. 2003; 289: 1389-1395. doi: 10.1001/ jama.289.11.1389

4. Huang Y, He Q, Yang LJ, Liu GJ, Jones A. Cardiopulmonary resuscitation (CPR) plus delayed defibrillation versus immediate defibrillation for out-of-hospital cardiac arrest. Cochrane Database Syst Rev. 2014; 2014(9): CD009803. doi: 10.1002/14651858.CD009803. pub2
5. Puri GD, Shyam KS, Mishra AK, Madhavan JS. Complete neurological recovery after delayed onset resuscitation in a normothermic witnessed arrest. Perfusion. 2013; 28: 253-235. doi: $10.1177 / 0267659112469550$

6. Nielsen N, Wetterslev J, Cronberg T, Erlinge D, Gasche Y, Hassager $\mathrm{C}$, et al. Targeted temperature management at $33^{\circ} \mathrm{C}$ versus $36^{\circ} \mathrm{C}$ after cardiac arrest. $N$ Engl J Med. 2013; 369: 2197-2206. doi: 10.1056/NEJMoa1310519 